\title{
MECANISMOS DE AÇÃO DOS ANTIPSICÓTICOS: HIPÓTESES DOPAMINÉRGICAS
}

\author{
MECHANISMS OF ANTIPSYCHOTIC MEDICATIONS: DOPAMINERGIC HYPOTHESES
}

\author{
Fabrício A. Moreira1 ${ }^{1}$ Francisco S. Guimarães ${ }^{2}$
}

\begin{abstract}
'Doutor em Ciências. Área de concentração Farmacologia. ${ }^{2}$ Docente. Departamento de Farmacologia. Faculdade de Medicina de Ribeirão Preto - USP.

Correspondência: Departamento de Farmacologia. Faculdade de Medicina de Ribeirão Preto - USP.

Av Bandeirantes, 3900 CEP 14049-900 Ribeirão Preto - SP, Brasil. farmoreira@yahoo.com.br
\end{abstract}

Moreira FA, Guimarães FS. Mecanismos de ação dos antipsicóticos: hipóteses dopaminérgicas. Medicina (Ribeirão Preto) 2007; 40 (1): 63-71.

RESUMO: Esta revisão discute algumas das principais hipóteses sobre os mecanismos de ação dos antipsicóticos no tratamento da esquizofrenia. São abordadas as teorias tentando diferenciar os antipsicóticos "atípicos" dos "típicos", como a do antagonismo de receptores $\mathrm{D}_{2}$ de dopamina e $5-\mathrm{HT}_{2}$ de serotonina, a da dissociação rápida do receptor $\mathrm{D}_{2}$ e, por fim, a teoria do agonismo parcial. Elas constituem um exemplo fascinante de como evoluem as idéias sobre os efeitos dos medicamentos. Além disso, mostram que há uma necessidade crescente de conceitos e termos básicos da Farmacologia para que se compreendam as diferenças observadas entre os antipsicóticos. Daí a justificativa para um texto que aborde os aspectos farmacológicos e as suas respectivas implicações.

Descritores: Antipsicóticos. Farmacologia. Esquizofrenia. História.

\section{1- INTRODUÇÃO}

Os medicamentos antipsicóticos, utilizados no tratamento da esquizofrenia, foram introduzidos na clínica na década de 1950. Inicialmente batizados de "Neurolépticos", ou "Tranqüilizantes Maiores" (em oposição aos benzodiazepínicos, os "Tranqüilizantes Menores"), eles são atualmentes agrupados em duas categorias: "Antipsicóticos Típicos" ou "Antipsicóticos Atípicos" 1,2 , nomes cujos significados serão discutidos. Atualmente, diversas hipóteses procuram critérios para diferenciar os antipsicóticos atípicos dos típicos, sendo importantes tanto para a utilização clínica quanto para a descoberta de novos medicamentos. Desta forma, a presente revisão tem por objetivo discutir as aplicações e limitações de cada uma dessas hipóteses, centradas nos neurotransmissores dopami- na e serotonina (5-hidroxitriptamina, 5-HT). Outros neurotransmissores (ex., glutamato), portanto, não serão discutidos. Enfim, cabe ressaltar que os conceitos, símbolos e termos farmacológicos empregados neste texto estão de acordo com o que preconiza a União Internacional de Farmacologia Básica e Clínica (International Union for Basic and Clinical Pharmacology; IUPHAR) ${ }^{3}$.

O marco inicial na história dos antipsicóticos foi a descoberta casual dos efeitos da Clorpromazina. Essa descoberta remonta da busca, pelo cirurgião francês Henry-Marie Laborit, de compostos capazes de atenuar o "choque" relacionado aos procedimentos cirúrgicos. Acreditava-se que essa reação seria o resultado de uma ativação autonômica devida ao estresse excessivo $^{2}$. Para atenuar essa reação, Laborit administrava aos pacientes um conjunto de substâncias que 
ele denominava de "Coquetel Lítico", que continha um anti-histamínico (Prometazina), dentre outras substâncias $^{2}$. Na busca de novos anti-histamínicos que pudessem ser utilizados com esse fim, foi enviado a Laborit um composto denominado Clorpromazina, sintetizado em 1950 por Paul Charpentier e testado farmacologicamente por Simone Courvoisier. Ao administrar esse composto, Laborit observou que os pacientes se declaravam "mais relaxados e calmos", mostrando "desinteresse" frente ao estresse do período pré-operató$\mathrm{rio}^{2}$. A partir dessas observações, foi sugerido o potencial uso da Clorpromazina como um "Tranqüilizante". Os primeiros estudos clínicos com esse medicamento foram realizados por Jean Delay e a Pierre Deniker, em Paris, com resultados bastante positivos, pois o novo fármaco restaurava significativamente a qualidade de vida dos pacientes psiquiátricos ${ }^{2}$.

$\mathrm{Na}$ década de 1950, enquanto iniciava-se a utilização da Clorpromazina na Europa, a Reserpina era introduzida na clínica na América do Norte. Porém, à Reserpina restaria "apenas" o interesse histórico e a utilidade como ferramenta farmacológica, sendo a Clorpromazina considerada o primeiro dos antipsicóticos. Ela pertence à classe química das fenotiazinas. Poucos anos após o início de sua utilização, uma nova classe foi introduzida, a das butirofenonas, tendo como protótipo o Haloperidol. Esses fármacos foram inicialmente denominados "neurolépticos", curiosamente não devido aos seus efeitos terapêuticos, mas sim devido aos seus efeitos colaterais de "natureza neurológica" 1 - os efeitos extrapiramidais, discutidos adiante. Os primeiros avanços para a compreensão de seus mecanismos de ação surgiram na década de 1960, conforme discutido a seguir.

\section{2- OS ANTIPSICÓTICOS E OS RECEPTORES DE DOPAMINA}

Os primeiros estudos propondo um mecanismo para os antipsicóticos foram conduzidos por Arvid Carlsson, agraciado com o Prêmio Nobel de Fisiologia e Medicina no ano 2000. Sabia-se que a Reserpina, que também apresenta ação antipsicótica; depletava monoaminas do encéfalo. Portanto, Carlsson e Lindqvist estudaram os efeitos dos "neurolépticos" sobre as monoaminas (mais precisamente das catecolaminas noradrenalina e dopamina). Em um artigo clássico publicado em $1963^{4}$, esses pesquisadores injetaram Clorpromazina e Haloperidol em camundongos e avaliaram a concentração dos metabólitos das monoaminas em homogenatos contendo os cérebros desses animais. A razão de quantificarem os metabólitos, mas não as próprias catecolaminas, é que estas são prontamente metabolizadas pela enzima monoaminooxidase (MAO) no meio intracelular, além da catecol$O$-metil-transferase (COMT) no meio extracelular. Portanto, a estratégia utilizada foi a de inibir a ação da MAO com injeções de nialamida. Desse modo, a noradrenalina e a dopamina eram metabolizadas apenas pela COMT, formando a normetanefrina e a 3-metoxitiramina, respectivamente. Esses metabólitos sofreriam subseqüientemente a ação da MAO, mas como esta estava inibida, eles se acumulavam e poderiam ser quantificados no encéfalo após os camundongos serem sacrificados. O resultado do estudo foi que as injeções agudas de Clorpromazina ou Haloperidol aumentavam significativamente a formação dos metabólitos de catecolaminas.

Sabia-se que os neurolépticos eram capazes de bloquear os efeitos de drogas que potencializam a dopamina, como os psicoestimulantes (Anfetamina e Cocaína) e a L-DOPA. Com base nisso, a proposta histórica de Carlsson foi que os antipsicóticos atuariam bloqueando o efeito das monoaminas. Sua hipótese foi que esses compostos aumentariam os níveis dos metabólitos de catecolaminas por bloquearem os respectivos receptores, o que ocasionaria uma ativação compensatória dos neurônios noradrenérgicos e dopaminérgicos, com aumento na taxa de renovação desses neurotransmissores. É interessante notar, portanto, que o antagonismo de dopamina não foi especificamente proposto nesse artigo. A interpretação, cautelosa, foi a de que o mecanismo seria o "antagonismo de receptores de monoaminas"

A menção mais direta à dopamina viria na década de 1970, quando se observou que a dopamina, e não a noradrenalina, era o neurotransmissor cujo metabolismo era aumentado pelos antipsicóticos ${ }^{5}$. Em seguida, consolidou-se a proposta de que os antipsicóticos tinham por mecanismo comum o antagonismo de receptores de dopamina. O neurofarmacologista Solomon Snyder observou que as estruturas das fenotiazinas, como a Clorpromazina, se superpunham à da dopamina, sugerindo que poderiam interagir com um mesmo receptor ${ }^{6,7}$. Mais evidências foram obtidas com experimentos in vitro, avaliando como os antipsicóticos marcados radiativamente se ligavam a membranas biológicas (ensaios de "binding"). Foi observado que o Haloperidol marcado era capaz de se ligar a sítios específicos em membranas do estriado de ratos, 
competindo com a dopamina ${ }^{8,9}$. Além disso, o Haloperidol poderia ser deslocado de seu sítio de ligação por diversos outros antipsicóticos, sugerindo que a dopamina, o Haloperidol e os demais antipsicóticos deveriam competir pelo mesmo sítio de ligação ${ }^{8,9}$. Foram determinadas a afinidade de diversos antipsicóticos por esse "possível receptor", avaliando-se a concentração necessária para deslocar dos receptores 50\% do Haloperidol marcado (concentração inibitória, $\mathrm{IC}_{50}$ ). Quanto menor a afinidade, maior a concentração necessária para se deslocar o ligante marcado (ou seja, maior a $\left.\mathrm{IC}_{50}\right)^{3}$.

Determinadas as $\mathrm{IC}_{50}$ para diversos antipsicóticos, observou-se que esses valores correlacionavamse diretamente tanto com as doses necessárias para antagonizar os efeitos de agonistas dopaminérgicos em ratos $^{8}$, quanto com as doses utilizadas na clínica (Figura 1$)^{9}$. O gráfico de correlação entre a afinidade $\left(\mathrm{IC}_{50}\right)$ pelo receptor de dopamina e a potência clínica dos antipsicóticos (Figura 1) tornou-se um clássico da farmacologia, consolidando a importância desse receptor para o mecanismo de ação desses fármacos. Em seguida, demonstrou-se também que, embora os antipsicóticos tenham afinidade por diversos outros receptores, como histamínicos, $\alpha$-adrenérgicos e serotoninérgicos, a potência clínica não se correlaciona com a afinidade por nenhum deles, reforçando a hipótese dos receptores de dopamina ${ }^{10}$.

Atualmente, são conhecidos diversos receptores de dopamina, todos eles acoplados a uma proteína $\mathrm{G}$, sendo eles $\mathrm{D}_{1}$ e $\mathrm{D}_{5}$, cujo mecanismo de transdução é a ativação da adenilato ciclase, e $\mathrm{D}_{2}$, $\mathrm{D}_{3}$ e $\mathrm{D}_{4}$, que inibem a adenilato cicla$\mathrm{se}^{11}$. A ação dos antipsicóticos deve-se, principalmente, mas não exclusivamente, ao antagonismo de receptores $\mathrm{D}_{2}$.

\section{3- AS VIAS DE DOPAMINA NO SIS- TEMA NERVOSO CENTRAL: IMPLICAÇÕES PARA OS EFEI- TOS TERAPÊUTICOS E COLA- TERAIS DOS ANTIPSICÓTICOS}

Enquanto o antagonismo de receptores de dopamina pode ser responsável pelo efeito terapêutico dos antipsicóticos, esse mecanismo também resulta em importantes efeitos colaterais. A razão para tais efeitos pode ser prontamente deduzida observando-se a distribuição e a função das vias de dopamina no encéfalo (Figura 2). Portanto, esse tópico será sucintamente discutido a seguir.

A dopamina é sintetizada por neurônios cujos corpos localizam-se no tronco cerebral e se projetam por diferentes vias. A via meso-límbico-cortical origina-se da área tegmental ventral e se projeta para um núcleo do estriado ventral chamado acúmbens (via meso-límbica). Ela também envia projeções para o lobo pré-frontal do córtex cerebral (via meso-cortical), sendo parte do chamado "feixe prosencefálico medial"12. Segundo a teoria dopaminérgica da esquizofrenia, os sintomas positivos seriam decorrentes de uma atividade excessiva de dopamina em receptores $\mathrm{D}_{2}$ no núcleo acúmbens, enquanto os sintomas negativos seriam decorrentes de uma redução na ativação de receptores dopaminérgicos no córtex pré-frontal ${ }^{13,14}$. De acordo com essa teoria, um antipsicótico ideal deveria reduzir a atividade dopaminérgica no núcleo acúmbens, atenuando os sintomas positivos (delírios, alucinações), mas intensificá-la no córtex pré-frontal, atenuando sintomas negativos (embotamento afetivo, déficits cognitivos) ${ }^{13,14,15}$.

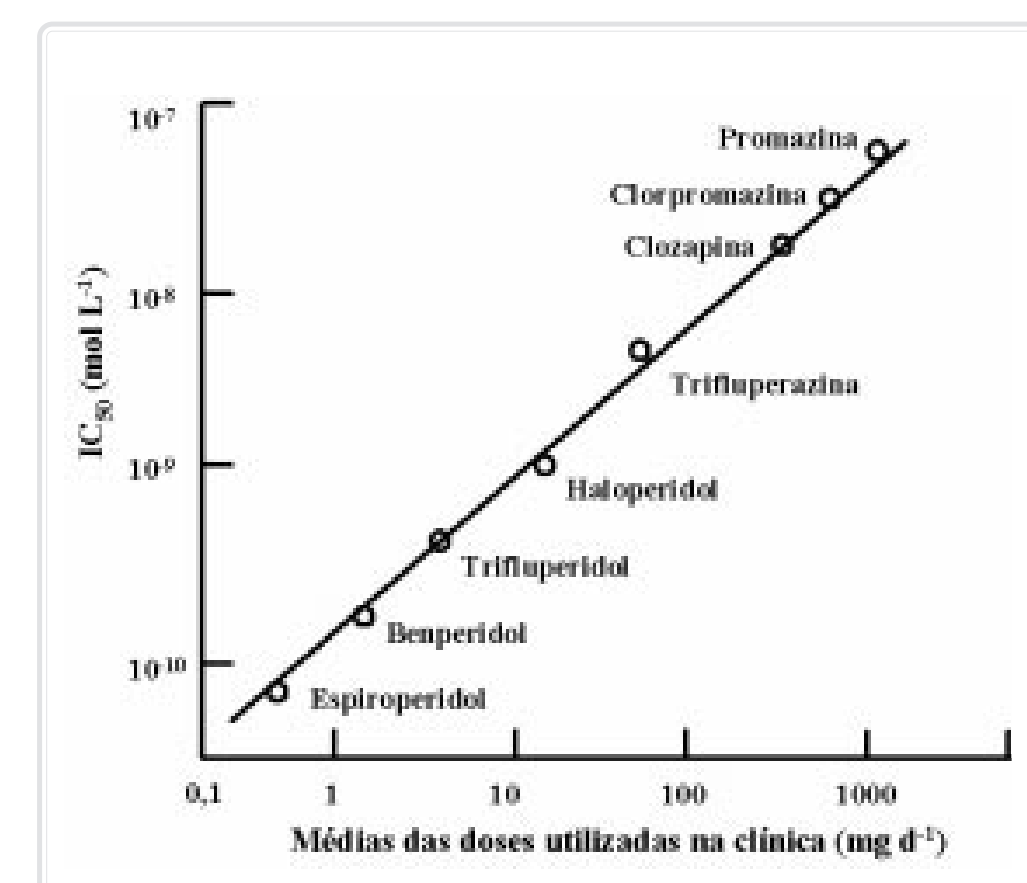

Figura 1: Correlação direta entre os valores de $I_{50}$ (concentrações necessárias para deslocar o Haloperidol do receptor de dopamina) e as doses terapêuticas de diversos antipsicóticos, sugerindo a ligação a esse receptor como um possível mecanismo para o efeito desses fármacos. Modificado de Seeman et al. ${ }^{9}$ 
Outra via dopaminérgica projeta-se da substância negra para o estriado dorsal (cauda-putamen, nos núcleos da base), sendo integrante do "sistema extrapiramidal" 16 . Os antipsicóticos, ao antagonizarem essa via, induzem os efeitos colaterais chamados "efeitos extrapiramidais", que são alterações motoras como bradicinesia e acatisia, constituindo a chamada "síndrome Parkinsoniana". Após o tratamento prolongado, essas drogas também induzem a discinesia tardia, efeitos colaterais caracterizados por movimentos involuntários da face e das extremidades ${ }^{17}$.

Além dos efeitos extrapiramidais, os antipsicóticos podem provocar, dentre outras alterações endócrinas, hiperprolactinemia e galactorréia, decorrentes do antagonismo da via dopaminérgica túbero-infundibular, que tonicamente inibe a secreção de prolactina ${ }^{18}$. Finalmente, há os efeitos colaterais decorrentes da ligação a outros receptores, uma vez que vários antipsicóticos são antagonistas de receptores receptores histamínicos, $\alpha$-adrenérgicos e muscarínicos. Como aspecto positivo, cabe mencionar que o antagonismo de receptores muscarínicos, presentes no estriado dorsal, pode resultar em um efeito "antiParkinsoniano", conferindo proteção contra os efeitos extra-piramidais ${ }^{19}$.

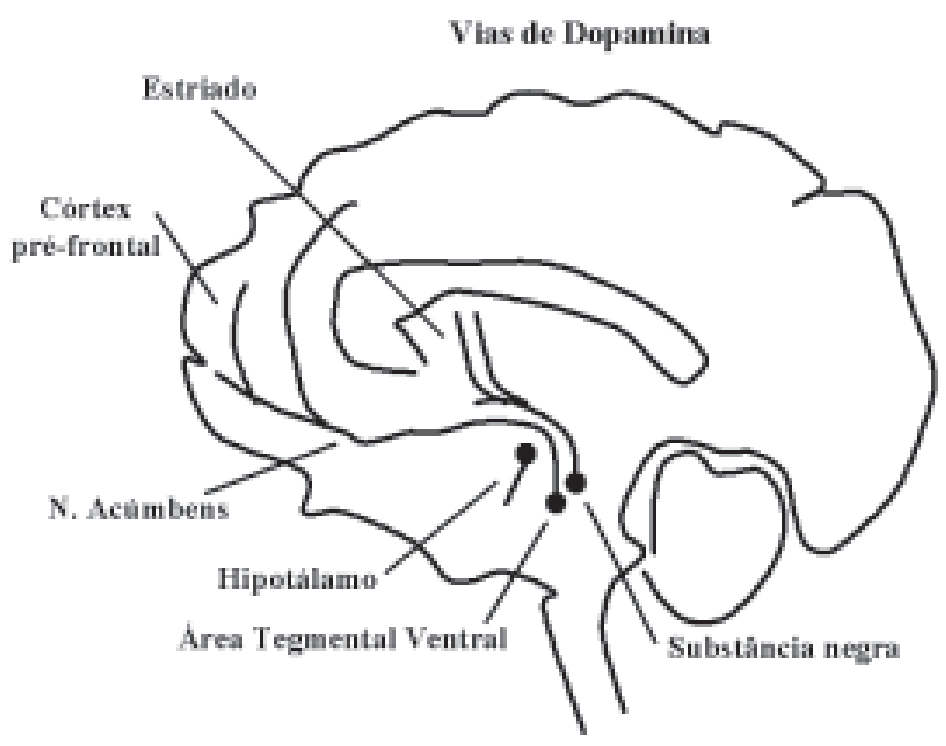

Figura 2: Representação esquemática das vias de dopamina no sistema nervoso central. A via meso-líbico-cortical projeta-se da área tegmental ventral para o núcleo acúmbens e para o córtex pré-frontal. A via nigroestriatal da substância negra para o estriado dorsal. Enfim, no hipotálamo, está indicada a via túbero-infundibular.

\section{4- A FARMACOLOGIA ATÍPICA}

A indução de efeitos extrapiramidais é uma característica tão marcante dos antipsicóticos típicos ("neurolépticos") que, inicialmente, acreditava-se que esse fosse um pré-requisito para a atividade terapêutica desses fármacos ${ }^{20}$. De fato, um importante estudo clínico demonstrou, em 1978, que os neurolépticos, além de serem eficazes apenas sobre os sintomas positivos da esquizofrenia, induziam siginificativos efeitos extrapiramidais ${ }^{21}$. Essa idéia, de que apenas compostos capazes de induzir efeitos extrapiramidais tivessem potencial terapêutico, fez com que um certo "candidato" a antipsicótico, denominado Clozapina, fosse visto com ceticismo, uma vez que ele não induzia efeitos extrapiramidais. $\mathrm{O}$ interesse nesse medicamento foi reduzido ainda mais após a observação de que ele poderia induzir agranulocitose $\mathrm{e}^{20}$.

Ironicamente, a Clozapina viria a ser o "padrão ouro" dos medicamentos antipsicóticos. Um outro estudo clínico clássico, realizado em 1988 pelo grupo de Herbert Meltzer, observou que a Clozapina, ao contrário dos demais fármacos, atenuava os sintomas positivos sem ocasionar efeitos extrapiramidais ${ }^{22}$. Além disso, apresentava eficácia contra os sintomas negativos da esquizofrenia ${ }^{22}$. Um perfil absolutamente "atípico" para um antipsicótico. Esse estudo viria a ter implicações significativas. Em primeiro lugar, a hipotése até então influente, de que os efeitos extra-piramidais seriam um prérequisito para a atividade antipsicótica, estava definitivamente abalada. Segundo, esse estudo ressuscitou o interesse na Clozapina. Essa substância, outrora rejeitada por não induzir efeitos extrapiramidais, passou a ser o protótipo na pesquisa de novos antipsicóticos. Assim, substâncias que, como a Clozapina, apresentam efeito terapêutico em doses que não induzem efeitos extrapiramidais, são atualmente classificados como "antipsicóticos atípicos", em contraposição aos "antipsicóticos típicos" ou "neurolépticos". Embora exista alguma controvérsia, atualmente são considerados compostos atípicos, dentre outros, a Olanzapina, a Quetiapina, a Risperidona, a Ziprazidona e o Aripiprazole. 
O principal critério para um que um antipsicótico tenha o "status" de atípico é uma diferença significativa entre as doses necessárias para induzir efeitos antipsicóticos e efeitos extrapiramidais ${ }^{15}$. Além disso, outros critérios são de interesse, como a eficácia sobre os sintomas negativos e a propensão do composto de induzir, galactorréia, ganho de peso, etc.

Diversas hipóteses tentam explicar essa "Farmacologia atípica". Quais mecanismos de ação diferenciam os antipsicóticos atípicos dos típicos? Essas hipóteses são de grande importância para a compreensão desses medicamentos e para o desenvolvimento racional de novos fármacos. Portanto, elas estão discutidas a seguir.

\section{5- A HIPÓTESE DO ANTAGONISMO DE RE- CEPTORES DE 5-HT E DE DOPAMINA}

A primeira hipótese farmacológica tentando diferenciar os antipsicóticos atípicos foi proposta por Meltzer e seus colaboradores em $1989^{23}$. Esse grupo procurou determinar a afinidade dos antipsicóticos pelos seus principais receptores, ou seja, os de dopamina e de 5-HT. Para tal, foram determinadas as constantes de equilíbrio de dissociação (Ki), um parâmetro farmacológico proporcional à $\mathrm{IC}_{50}$ (discutida na $\mathrm{Se}$ ção 2). Nesse artigo, os valores de Ki foram expressos na forma logarítmica negativa, chamada pKi (ou seja, pKi $=-\log \mathrm{Ki}$ ), que é proporcional à afinidade pelo receptor (Tabela I). Observou-se que, em média, os antipsicóticos atípicos e típicos apresentavam afinidades semelhantes pelos receptores $5 \mathrm{HT}_{2}$. Porém, os atípicos apresentavam menor afinidade pelos receptores $\mathrm{D}_{2}$ (menor $\mathrm{pKi}$ ). Segundo a proposta desse trabalho, os antipsicóticos poderiam ser diferenciados em típicos ou atípicos pela razão entre os valores de pKi para os receptores $5 \mathrm{HT}_{2}$ e $\mathrm{D}_{2}$ : Uma elevada $\mathrm{pKi}$ (ou seja, afinidade) do antipsicótico pelos receptores $5 \mathrm{HT}_{2}$, comparada ao $\mathrm{D}_{2}$, seria o indício de um composto com propriedades de antipsicótico atípico, pois o antagonismo $5 \mathrm{HT}_{2}$ seria um fator de proteção contra o antagonismo da dopamina ${ }^{23,24,25}$. A afinidade pelos receptores $\mathrm{D}_{2}$ seria necessária para o efeito antipsicótico, mas uma afinidade maior pelo receptor $5 \mathrm{HT}_{2}$ conferiria a um antipsicótico o caráter de atípico ${ }^{23,24,25}$.

Essa importante hipótese vem exercendo grande influência no estudo e na pesquisa de novos antipsicóticos ${ }^{25}$. Porém, ela pode ser confrontada por outra proposta, conforme discutido a seguir.
Tabela I: Valores médios de "-log Ki" para os receptores $5 \mathrm{HT}_{2}$ e $\mathrm{D}_{2}$, determinados separadamente para os antipsicóticos típicos e atípicos (valores maiores de "-log $\mathrm{K}_{\mathrm{i}}$ " significam maior afinidade pelo receptor). Os atípicos apresentam menor afinidade por $D_{2}$ e maior razão de afinidades $5 \mathrm{HT}_{2} / \mathrm{D}_{2}$. *Diferença significativa $(p<0.05)$ entre atípicos e típicos, conforme determinado por análise de variância. Modificado de Meltzer et al. ${ }^{23}$

\begin{tabular}{lcc}
\hline Receptor & Típicos $(\mathrm{n}=13)$ & Atípicos $(\mathrm{n}=7)$ \\
\hline$-\log \mathrm{K}_{\mathrm{i}} 5 \mathrm{HT} \mathrm{T}_{2}$ & $8,11 \pm 0,71$ & $8,57 \pm 0,91$ \\
$-\log \mathrm{K}_{\mathrm{i}} \mathbf{D}_{2}$ & $8,89 \pm 0,51$ & $7,18 \pm 0,87^{*}$ \\
Razão $5 \mathrm{HT}_{2} / \mathbf{D}_{2}$ & $0,91 \pm 0,08$ & $1,20 \pm 0,05^{*}$ \\
\hline
\end{tabular}

\section{6- A HIPÓTESE DA BAIXA AFINIDADE PE- LOS RECEPTORES $\mathrm{D}_{2}$}

Não obstante a importância da proposta de Meltzer, novas hipóteses vem sendo elaboradas para diferenciar os antipsicóticos. Por exemplo, segundo Shitij Kapur et al. ${ }^{13,26,27}$, o antagonismo de receptores de 5-HT não deve ser um fator necessário para conferir a um antipsicótico o caráter de atípico. De acordo com esses autores, a teoria de Meltzer não explica, por exemplo, os efeitos da Amisulpirida. Levando-se em conta as diferenças entre as doses para induzir efeitos terapêuticos e extrapiramidais, esse antipsicótico é considerado atípico ${ }^{28}$. Porém, ele não se enquadra na teoria de Meltzer, por ser um antagonista seletivo para receptores $\mathrm{D}_{2}$, e não um antagonista receptores $5 \mathrm{HT}_{2} /$ $\mathrm{D}_{2}$. Seria possível, portanto, diferenciar os antipsicóti$\cos$ apenas pelas afinidades pelo receptor $\mathrm{D}_{2}$ ?

O primeiro passo para se responder essa pergunta é entender como os antipsicóticos ocupam os receptores $\mathrm{D}_{2}$. Para isso, é preciso mencionar os importantes estudos de neuroimagem com pacientes esquizofrênicos sob tratamento, realizados por Farde et al. ${ }^{29,30}$. Em tais estudos, esses autores deduziram o percentual de receptores $\mathrm{D}_{2}$ ocupados, no estriado, por doses terapêuticas de diversos antipsicóticos. Doses terapêuticas de Clozapina, que não induziam efeitos extrapiramidais, resultavam em uma ocupação de cerca de $65 \%$ dos receptores. Já as doses terapêuticas de antipsicóticos típicos, que induzem efeitos extrapiramidais, faziam com que mais de $80 \%$ dos receptores fossem ocupados. Valores muito próximos 
foram obtidos em modelos animais preditivos de atividade antipsicótica (cerca de $70 \%$ de ocupação na resposta de esquiva condicionada) e de efeitos extrapiramidais (maior que $80 \%$ no modelo da catalepsia) ${ }^{31}$.

Portanto, aproximandamente, uma ocupação de receptores acima $65 \%$ parece ser necessária para o efeito terapêutico, enquanto acima de $80 \%$ resulta em efeitos extrapiramidais. Ou seja, a ocupação de receptores - e, portanto, a dose - necessária para o efeito terapêutico é, em geral, menor do que a necessária para induzir efeitos extrapiramidais. Isso mostra, mais uma vez, como era equivocada a antiga idéia de que a capacidade de induzir efeitos extrapiramidais seria um pré-requisito para a atividade antipsicótica. Pode-se concluir que o perfil ideal para um antipsicótico é uma grande diferença entre a dose necessária para ocupar $65 \%$ (limiar para efeito terapêutico) e a necessária para ocupar $80 \%$ (limiar para efeitos extrapiramidais) dos receptores $\mathrm{D}_{2}$ no estriado.

$\mathrm{Na}$ busca de mecanismos farmacológicos que explicassem essas diferenças, Kapur determinou as constantes $\mathrm{K}_{\mathrm{i}}$ (ou seja, as afinidades - ver Seção 4) de diversos antipsicóticos para os receptores $\mathrm{D}_{2}$. Mas, além disso, foram também determinadas as respectivas constantes de associação $\left(\mathrm{K}_{+1}\right.$ ou $\left.\mathrm{K}_{\text {on }}\right)$ e dissociação $\left(\mathrm{K}_{-1}\right.$ ou $\left.\mathrm{K}_{\text {off }}\right)$. $\mathrm{O}$ valor de $\mathrm{K}_{\mathrm{i}}$ (maior quanto menor for a afinidade) resulta da razão entre as constantes $\mathrm{K}_{-1}$ e $\mathrm{K}_{+1}\left(\mathrm{~K}_{\mathrm{i}}=\mathrm{K}_{-1} / \mathrm{K}_{+1}\right)$. Enquanto $\mathrm{K}_{\mathrm{i}}$ é uma medida de concentração, as constantes $\mathrm{K}_{-1}$ e $\mathrm{K}_{+1}$ indicam, respectivamente, as velocidades nas quais uma substância se dissocia de, ou se associa a, 50\% dos receptores.

Conforme esperado, os antipsicóticos atípicos apresentaram maior $\mathrm{K}_{\mathrm{i}}$ (menor afinidade) pelo receptor $\mathrm{D}_{2}$. Porém, a novidade desses estudos foi que, além disso, os atípicos se distinguiam porque se dissociavam mais rapidamente do receptor (ou seja apresentam maior $\mathrm{K}_{-1}$ ) do que os típicos ${ }^{26,27}$.

Esse fato, de que os antipsicóticos atípicos se dissociam mais facilmente do receptor $\mathrm{D}_{2}$, poderia explicar as observações prévias de que esses fármacos ocupam menos os receptores no estriado, induzindo menos efeitos extrapiramidais ${ }^{29,30}$. Assim, ao contrário da proposta de Meltzer ${ }^{25}$ (afinidade $5 \mathrm{HT}_{2} / \mathrm{D}_{2}$ ), a hipótese da dissociação, de Kapur, prevê que um antipsicótico pode ser atípico mesmo sendo seletivo para o receptor $\mathrm{D}_{2}^{27}$. Basta que ele se dissocie do receptor mais facilmente do que a dopamina, de modo a ser deslocado por esse neurotransmissor quando ele fosse liberado. Isso permitiria que a dopamina se li- gasse ao receptor e exercesse sua função fisiológica no estriado. De acordo com essa hipótese, os atípicos seriam capazes de ocupar os receptores de dopamina no núcleo acúmbens (via meso-límbica), atenuando os sintomas positivos da esquizofrenia. Porém, eles não prejudicariam a função dopaminérgica no estriado (via nigro-estriatal), pois a dopamina liberada deslocaria o antipsicótico (Figura 3). Embora, na esquizofrenia, a liberação dopamina (via meso-límbica) possa estar aumentada no acúmbens, a liberação desse neurotransmissor pela via nigro-estriatal já é fisiologicamente elevada, comparada à via meso-límbica ${ }^{15}$. Desse modo, o neurotransmissor atingiria concentrações sinápticas capazes de competir pela ocupação do receptor no estriado dorsal, deslocando o antipsicótico (Figura 3). Como resultado final, a dopamina seria antagonizada no núcleo acúmbens, mas exerceria seus efeitos fisiológicos normalmente no estriado dorsal.

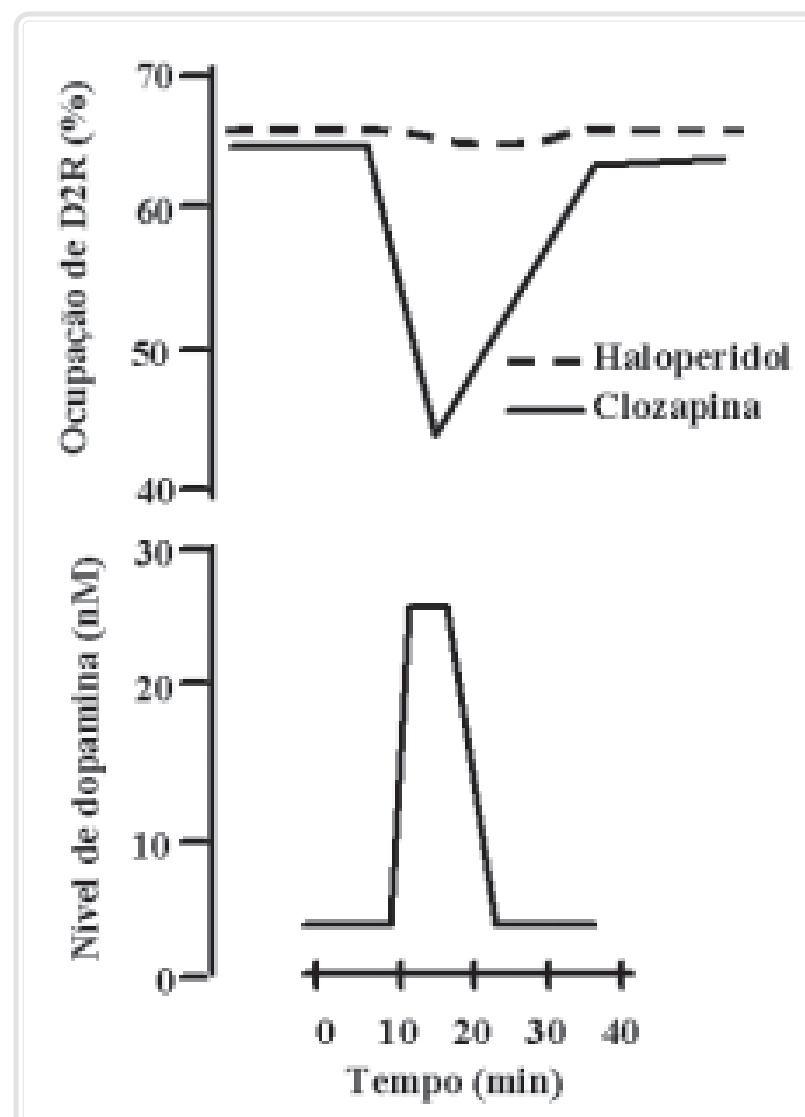

Figura 3: Simulação computadorizada do percentual de receptores $\mathrm{D}_{2}$ ocupados pelo Haloperidol e pela Clozapina após um pulso de liberação de dopamina no estriado. Ao contrário do Haloperidol, a Clozapina se dissocia facilmente do receptor, de modo a permitir a ação da dopamina. Isso implicaria em menor incidência de efeitos extrapiramidais. Modificado de Kapur e Seemann2. 
Essa hipótese, porém, ainda não teve o mérito da de Meltzer, que já serviu de plataforma para a descoberta de novos antispicóticos atípicos. Sendo mais recente, ela aguarda mais dados que possam sustentála ou refutá-la.

\section{7- OUTROS MECANISMOS DE AÇÃO}

A discussão anterior girou em torno de fármacos que atuam como antagonistas de receptores $\mathrm{D}_{2}$. Porém, a interpretação dos trabalhos de Farde et al. ${ }^{27,28}$, de que os efeitos extrapiramidais ocorrem quando há ocupação acima de $80 \%$ de receptores $\mathrm{D}_{2}$ no estriado, já não abrange todos os antipsicóticos. É possível que um composto tenha um perfil característico dos atípicos, mesmo ocupando quase $100 \%$ de receptores $\mathrm{D}_{2}$, em doses terapêuticas ${ }^{32}$. O primeiro exemplo desse perfil, utilizado na clínica, é o Aripiprazol. Embora esse fármaco possa agir em diversos receptores, uma possível explicação para o seu perfil está no modo de ação nos próprios receptores $\mathrm{D}_{2}$, que difere dos demais ${ }^{32,33}$.

Até aqui, construiu-se a idéia de que os efeitos extrapiramidais devem ocorrer quando há elevada ocupação de receptores $\mathrm{D}_{2}$. Porém, essa relação ocupação-efeito é uma extrapolação, que parte do princípio de que todos os antipsicóticos sejam antagonistas desses receptores. Isso pode ser aplicado aos demais antipsicóticos, pois todos, de fato, parecem atuar por esse mecanismo. Porém, quanto ao Aripiprazol, estudos in vitro e em animais experimentais sugerem que ele não atue como um antagonista nos receptores $\mathrm{D}_{2}$, mas sim como um agonista parcial ${ }^{33}$. Ocupação, portanto, não é apenas antagonismo ${ }^{32}$. E, nesse caso, os efeitos terapêuticos não se correlacionam da mesma maneira com o percentual de ocupação de receptores.

A propriedade de um agonista de ativar um receptor e induzir efeito farmacológico denomina-se eficácia intrínseca ${ }^{3}$. Um agonista pode ser pleno, induzindo o efeito máximo que os sistema pode permitir (possui elevada eficácia intrínseca), ou parcial, induzindo um efeito de menor magnitude (possui reduzida eficácia intrínseca). Um antagonista possui eficácia "zero". Os agonistas parciais apresentam um perfil farmacológico interessante. Quando competindo com um agonista pleno, eles agem de forma semelhante à que agiria um antagonista, inibem o efeito farmacológico (por ativar o receptor menos que o agonista pleno). Porém, quando nenhum agonista pleno está pre- sente, o agonista parcial, ao contrário dos antagonistas, age ativando o receptor, induzindo uma resposta de magnitude discreta.

À luz da teoria dopaminérgica da esquizofrenia, é possível que um agonista parcial atue conforme descrito a seguir ${ }^{34}$. No núcleo acúmbens, ele pode ocupar os receptores $\mathrm{D}_{2}$ e reduzir a ativação ocasionada pelo excesso de dopamina, aliviando os sintomas positivos, da mesma forma como fazem os antagonistas. Porém, no estriado, enquanto os demais antipsicóticos atenuam significativamente a ativação dos receptores $\mathrm{D}_{2}$ após ocupá-los no lugar da dopamina, um agonista parcial pode ocupar esses receptores e mantêlos ativados (ainda que de forma menos eficaz do que a própria dopamina). O resultado é a preservação das funções do sistema extrapiramidal, já que, embora a dopamina não possa se ligar, o fármaco cumpre parcialmente a função do ligante endógeno. Além disso, um agonista parcial pode ativar os receptores no córtex pré-frontal, se a liberação local de dopamina estiver reduzida nessa estrutura, aliviando os sintomas negativos.

A idéia de se utilizar agonistas parciais dos receptores $\mathrm{D}_{2}$ no tratamento da esquizofrenia não é recente $^{34,35}$, e novos fármacos que atuam como agonistas parciais estão sendo desenvolvidos. Porém, embora essa seja uma possível tendência para o desenvolvimento de novos fármacos, ainda é preciso avaliar se esse mecanismo de ação realmente implicará em vantagens terapêuticas consistentes, em comparação aos demais antipsicóticos. De qualquer maneira, os agonistas parciais são elegantes do ponto de vista da Farmacologia, e dão continuidade ao "ciclo", por trazerem questionamentos às teorias anteriores sobre os mecanismos de ação dos antipsicóticos.

\section{8- CONCLUSÃO}

A presente revisão abordou as propostas mais relevantes para explicar os mecanismos de ação dos antipsicóticos e para diferenciar os atípicos dos típicos. Foram discutidas as teorias do antagonismo de receptores $\mathrm{D}_{2}$ e $5-\mathrm{HT}_{2}$, da dissociação rápida do receptor $\mathrm{D}_{2} \mathrm{e}$, por fim, do agonismo parcial. Elas constituem um exemplo fascinante de como evoluem as hipóteses, e mostram que o conhecimento dos conceitos básicos da Farmacologia é cada vez mais importante para que se compreendam as ações desses medicamentos. 
Moreira FA, Guimarães FS. Mechanisms of antipsychotic medications: dopaminergic hypotheses. Medicina (Ribeirão Preto) 2007; 40 (1): 63-71.

ABSTRACT: This review discusses some of the main hypothesis about the mechanisms of action of antipsychotics in the treatment of schizophrenia. The main theories try to identify mechanisms to differentiate between the "atypical" and "typical" antipsychotics, such as the antagonism of $D_{2}$ and $5-H_{2}$ receptors, the rapid dissociation from the $D_{2}$ receptor and the partial agonism. They constitute an interesting example of how ideas evolve to explain the effects of diverse medicines. Moreover, these theories show how important are the concepts and terms from basic Pharmacology for understanding the differences among the antipsychotics. Hence, the importance of an article approaching the pharmacological aspects and its implications.

Keywords: Antipsychotics. Pharmacology. Schizophrenia. History.

\section{REFERÊNCIAS}

1 - King C, Lakshmi NP, Voruganti NP. What is in a name? The evolution of the nomenclature of antipsychotic drugs. J Psychiatry Neurosci 2002; 27: 168-75.

2 - López-Muñoz F, Alamo C, Rubio G, Cuenca E. Half a century since the clinical introduction of chlorpromazine and the birth of psychopharmacology. Progr Neuropsychopharmacol Biol Psychiatry 2004; 28: 205-8.

3 - Neubig RR, Spedding M, Kenakin T, Christopoulos A. International Union of Pharmacology Committee on Receptor Nomenclature and Drug Classification. XXXVIII. Update on Terms and Symbols in Quantitative Pharmacology. Pharmacol Rev 2003; 55: 597-606.

4 - Carlsson A, Lindqvist M. Effect of Chlorpromazine and Haloperidol on formation of 3-methoxytyramine and normetanephrine in mouse brain. Acta Pharmacol Toxicol 1963; 20: 140-4.

5 - Anden NE, Butcher SG, Corrodi H, Fuxe K, Ungerstedt U. Receptor activity and turnover of dopamine and noradrenaline after neuroleptics. Eur J Pharmacol 1970; 11: 303-14.

6 - Snyder SH, Banerjee SP, Yamamura HI, Greenberg D. Drugs, neurotransmitters, and schizophrenia. Science 1974; 184: 1243-53.

7 - Feinberg AP, Snyder SH. Phenotiazine drugs: Structureactivity relationships explained by a conformation that mimics dopamine. Proc Natl Acad Sci USA 1975; 72: 1899-903.

8 - Creese I, Burt DR, Snyder SH. Dopamine receptor binding predicts clinical and pharmacological potencies of ant schizophrenic drugs. Science 1976; 192: 481-3.

9 - Seeman P, Lee T, Chau-Wong M, Wong K. Antipsychotic drug doses and neuroleptic/dopamine receptors. Nature 1976; 261: 717-9.

10 - Peroutka SJ, Snyder SH. Relationship of neuroleptic drug effects at brain dopamine, serotonin, $\alpha$-adrenergic and histamine receptors to clinical potency. Am J Psychiatry 1980; 137: 1518-22.
11 - Seeman P, Van Tol HHM. Dopamine receptor pharmacology. Trends Pharmacol Sci 1994; 15: 264-70.

12 - Wise RA. Forebrain substrates of reward and motivation. J Comp Neurol 2005; 493: 115-21.

13 - Kapur S. Psychosis as a state of aberrant salience: A framework linking biology, phenomenology, and pharmacology in schizophrenia. Am J Psychiatry 2003; 160: 13-23.

14 - Kapur S. How antipsychotics become anti-"psychotic" from dopamine to salience to psychosis. Trends Pharmacol Sci 2004; 25: 402-6.

15 - Strange PG. Antipsychotic drugs: Importance of dopamine receptors for mechanisms of therapeutic actions and side effects. Pharmacol Rev 2001; 53: 119-33.

16 - Heimer L. A new anatomical framework for neuropsychiatric disorders and drug abuse. Am J Psychiatry 2003; 60: 172639.

17 - Casey DE. Motor and mental aspects of acute extrapyramidal syndromes. Acta Psychiatr Scand 1994; 89(suppl 380): 14-20.

18 - Baptista T. Body weight gain induced by antipsychotic drugs: mechanisms and management. Acta Psychiatr Scand 1999; 100: 3-16.

19 - Reynolds GP. Receptor mechanisms in the treatment of schizophrenia. J Psychopharmacol 2004; 18: 340-5.

20 - Hippius H. The history of clozapine. Psychopharmacology, 99:S3-S5, 1989

21 - Johnstone EC, Frith CD, Crow TJ, Carney MWP, Price JS Mechanism of the antipsychotic effect in the treatment of acute schizophrenia. Lancet 1978; 311: 848-51.

22 - Kane J, Honigfeld G, Singer J, Meltzer HY. The Clozaril Collaborative Group. Clozapine for the treatment-resistant schizophrenic. A double-blind comparison with chlorpromazine. Arch Gen Psychiatry 1988; 45: 789-96.

23 - Meltzer HY, Matsubara S, Lee JC, Classification of typical and atypical antipsychotic drugs on the basis of dopamine D-1, D-2 and serotonin-2 pKi values. J Pharmacol Exp Ther 1989; 251: 238-46. 
24 - Meltzer HY. Clinical studies on the mechanisms of action of clozapine: the dopamine-serotonin hypothesis of schizophrenia. Psychopharmacology 1989; 99: S18-S19.

25 - Meltzer HY, Li Z, Kaneda Y, Ichikawa J. Serotonin receptors: their key role in drugs to treat schizophrenia. Prog Neuropsychopharmacol Biol Psychiatry 2003; 27:1159-72.

26 - Kapur S, Seeman P. Antipsychotic agents differ in how fast they come on and off the dopamine D2 receptors. Implications for atypical antipsychotic action. J Psychiatry Neurosci $2000 ; 25: 161-6$.

27 - Kapur S, Seeman P. Does fast dissociation from the dopamine D2 receptor explain the action of atypical antipsychotics? A new hypothesis. Am J Psychiatry 2001; 158: 360-9.

28 - Leucht S; Pitschel-Walz G; Engel GR; Kissling V. Amisulpride, an unusual atypical antipsychotic: a meta-analyisis of randomized controled trials. Am J Psychiatry 2002; 159: 18090.

29 - Farde L, Fritz-Axel W, Halldin C, Sedvall G. Central D2dopamine receptor occupancy in schizophrenia patients treated with antipsychotic drugs. Arch Gen Psychiatry 1988; 45: 71-6.

30 - Farde L, Nordström AL, Wiesel FA, Pauli S, Halldin C, Sedvall G. Positron emission tomographic analysis of central D1 and D2 dopamine receptor occupancy in patients treated with classical neuroleptics and clozapine. Relation to extrapyramidal side effects. Arch Gen Psychiatry 1992; 49: 538-44.
31 - Wadenber MLG; Kapur S, Soliman A; Jones C; Vaccarino F: Dopamine D2 receptor occupancy predicts catalepsy and the suppression of conditioned avoidance response behaviour in rats. Psychopharmacology 2000; 150: 422-9.

32 - Gründer G, Carlsson A, Wong DF. Mechanism of new antipsychotic medications. Occupancy is not just antagonism. Arch Gen Psychiatry 2003; 60: 974-7.

33 - Burris KD, Molski TF, Xu C, Ryan E, Tottori K, Kikuchi T et al. Aripiprazole, a novel antipsychotic, is a high-affinity partial agonist at human D2 receptors. J Pharmacol Exp Therap 2002; 302: 381-9.

34 - Ohlsen RI; Pilowsky LS. The place of partial agonism in psychiatry: recent developments. J Psychopharmacol 2005; 19: 408-13.

35 - Tamminga CA. Partial dopamine agonists in the treatment of psychosis. J Neural Transm 2002; 109: 411-20.

Recebido para publicação em 31/08/2006

Aprovado para publicação em 17/10/2006 